\title{
Contemporary techniques for nerve transfer in facial reanimation
}

\author{
William Dougherty ${ }^{1}$, Robert Liebman ${ }^{1}$, Myriam Loyo $^{2}$ \\ 'Facial Plastic and Reconstructive Surgery Division, Department of Otolaryngology-Head and Neck Surgery, Eastern Virginia \\ Medical School, Norfolk, VA 23507, USA. \\ ${ }^{2}$ Facial Plastic and Reconstructive Surgery Division, Department of Otolaryngology- Head and Neck Surgery, Oregon Health \& \\ Science University, Portland, OR 97239, USA.
}

Correspondence to: Dr. Myriam Loyo, Department of Otolarynology-Head and Neck Surgery, Division of Facial Plastic and Reconstructive Surgery, Oregon Health and Science University, 3303 SW Bond Avenue, Portland, OR 97239, USA.

E-mail: loyo@ohsu.edu

How to cite this article: Dougherty W, Liebman R, Loyo M. Contemporary techniques for nerve transfer in facial reanimation. Plast Aesthet Res 2021;8:6. http://dx.doi.org/10.20517/2347-9264.2020.195

Received: 16 Oct 2020 Accepted: 11 Dec 2020 Published: 13 Jan 2021

Academic Editor: Jonathan R. Clark Copy Editor: Miao Zhang Production Editor: Jing Yu

\begin{abstract}
Nerve transfer procedures have the potential to restore innervation and function to the native facial musculature. This review summarizes the existing literature on facial nerve injury, regeneration, and reinnervation techniques with a focus on nerve transfer and its various options. Utilizing nerve transfer as early as possible, and ideally during the first 12 months of paralysis, is recommended. Prolonged paralysis is frequently not amenable to nerve transfer. The masseteric nerve provides excellent smile restoration after coapation to midfacial nerve branches with minimal morbidity. Several modifications to the hypoglossal nerve transfer have been described to limit its morbidity in speech and swallowing. The cross facial nerve, while appealing and able to achieve a true spontaneous smile, has limitations in terms of axonal load, time to reinnervation, unpredictable outcomes, and utility in older patients, who have less regenerative potential. Finally, there are exciting new developments in the field, combining reanimation techniques to harness advantages of various donor nerves, and research in peripheral nerve regeneration.
\end{abstract}

Keywords: Facial nerve, facial reanimation, facial paralysis, nerve transfer, masseter, cross facial nerve graft, hypoglossal 


\section{INTRODUCTION}

Facial paralysis has considerable functional and psychological morbidity ${ }^{[1]}$. Facial nerve anatomy and physiology is among the most complex in the human body. In the past 30 years, significant advances have been made in the fields of neural regeneration and facial reinnervation. Although direct nerve repair remains ideal, it is not always feasible. In such cases, nerve transfer, or nerve substitution, can be performed with good results. Although the ideal timing for nerve transfers has not yet been established, utilizing reinnervation as early as possible and within the first 12 months of paralysis is a common goal. This review is focused on understanding nerve transfer procedures for facial reanimation. The masseteric branch of the trigeminal nerve (cranial nerve V), hypoglossal (cranial nerve XII), and contralateral facial nerve (cranial nerve VII) nerve transfers as well as combination procedures are herein reviewed. In planning for facial reanimation, it is critical for the surgeon to consider the underlying etiology, prognosis for spontaneous recovery, and duration of facial nerve dysfunction. The differential diagnosis for facial nerve paralysis is beyond the scope of this review. However, understanding the time to reinnervation and axonal load to reinnervate the targeted muscle are important guiding principles discussed. The surgical techniques, expected outcomes, and associated morbidities will be discussed. Included is a brief review of nerve physiology and repair as well as nerve grafts repair. Emerging techniques are discussed throughout.

\section{NERVE INJURY}

The peripheral motor nervous system is composed of motor neurons which have their cell bodies in the spinal cord and axons extending to the distal muscles they innervate. Axons projecting from nerve cell bodies are sheathed by glial Schwann cells which coat the axons with myelin protein and can produce nerve growth factor among other supportive factors. Stromal cells comprise a scaffold that structurally supports axons along their course. These stromal cells are organized into specific layers. These supportive layers are critical to axonal regeneration. The deepest layer of stromal cells, termed endoneurium, surround and support individual axons. The next layer comprises the perineurium which organizes endoneurium bound axons into nerve fascicles. The outer-most stromal cell group forms the epineurium. Epineurium exists between fascicles (epifascicular epineurium) as well as epineural epineurium which surrounds the nerve trunks.

Seddon is credited with the first classification scheme of nerve injury ${ }^{[2]}$. The classification scheme was expanded on and popularized by Sunderland who introduced the stromal cell layers in axons ${ }^{[3]}$. Sunderland's classification contains five categories using Roman numerals I-V: corresponding to increasing degrees of severity. Class I, termed neuropraxia, typically produced by traction or compression on a nerve without disruption of the integrity of the nerve. The next grade (II) of injury is termed axonotmesis and involves disruption of the axon. With axonal disruption, Wallerian degeneration will take place over the ensuing one to three days. Wallerian degeneration is a process in which the axons and myelin distal to the level on injury degenerate. Schwann cells undergo changes in gene expression following axonal injury. They begin to produce neurotrophic proteins involved in the regenerative process ${ }^{[4]}$. In Sunderland class II injury the stromal tissues are intact and axon regeneration will occur with precision to the correct motor unit. Thus, synkinesis is avoided ${ }^{[5]}$. Sunderland class III-V injuries are progressively severe forms of neurotmesis and involve injury to the endoneurium, perineurium, and epineurium structures respectively. Sunderland III and IV injuries will heal spontaneously but class IV will have increasing degrees of scarring and hence worse recovery and higher rates of synkinesis. Sunderland IV and V are frequently thought to require surgical intervention. Currently, these classes can only be diagnosed histologically. It is not possible to use electrophysiological testing to distinguish Sunderland classes, especially early after injury. As early nerve repair leads to improve outcomes, clinical evaluation remains key in the management of facial nerve lesion. The Sunderland classification helps conceptualize the damage necessary to repair after peripheral nerve injury. More recently, a sixth classification of injury has been proposed to describe more proximal insults producing mixed patterns of injury incorporating two or more of the other five classes ${ }^{[6]}$. 
There are important considerations for functional recovery with regards to the end-organ motor foot plate. The motor end plate is preserved by trophic factors secreted by then distal ends of intact axons ${ }^{[7]}$. The motor end plate structure is typically maintained for up to one year after denervation. Later, after about 18 24 months following denervation without reinnervation, there will be permanent damage to the motor end plates and irreversible atrophy of the end-organ muscle tissue ${ }^{[5]}$.

\section{NERVE REGENERATION}

The regeneration of peripheral nerves is slow and usually incomplete. Axons regenerate at an average rate of $1 \mathrm{~mm}$ per day. Because of this, peripheral nerve repair is rarely successful over long distances. The process for peripheral nerve regrowth is complex and requires molecular, cellular, and microenvironment changes. If the distal nerve stump and targeted muscle remain denervated for a long period, their capacity for regeneration is severely affected. Following nerve injury, the distal stump is progressively disintegrated. This destruction creates space for the eventual ingrowth of a new axon ${ }^{[8]}$. There is upregulation of glialderived neurotrophic factor and brain-derived neurotrophic factor which drive axonal regeneration ${ }^{[9,10]}$. Following higher grades of axonal injury, the proximal nerve cell bodies undergo several gene expression changes to adopt a regenerative phenotype ${ }^{[1]}$. This includes the upregulation of actin, tubulin, and GAP43 proteins. A growth cone is formed at the end of the proximal stump. Filopodia are formed at the growth cone and function to sample the surrounding milieu as the growth cone proceeds towards the distal nerve stump ${ }^{[12]}$. Growth cones are directed through the stroma and surrounding tissue by a variety of chemoattractants and repellants ${ }^{[13]}$. After recruiting macrophages which assist with phagocytosis to clear away the damaged axon and myelin debris, Schwann cells, in a regenerative mode, will grow along the endoneurium. This Schwann cell growth takes the form of a hollow tube, termed bands of Bunger, and assists with creating a path for the regenerating axon ${ }^{[14]}$. Schwann cells also produce factors that guide the growth of the regenerating axon through the bands of Bunger towards the distal stump target. Regeneration of axons into wrong endoneurial tubes and end organs leads to worse functional outcomes. Once the regenerated axon has reached its target, the Schwann cell reverts to supportive phenotype and assists with re-myelination of the axon ${ }^{[5]}$.

Many observations regarding factors influencing successful nerve regeneration have been made. The distance of a nerve lesion from its targeted tissue has a significant impact on recovery. The further the injury is from the target tissue the lower the chance of meaningful regeneration ${ }^{[15]}$. Studies of irradiated nerves demonstrate consensus in their results: a slowed but capable regenerative capability ${ }^{[16,17]}$. As previously mentioned, the degree of nerve injury has a major impact on success of regeneration ${ }^{[18]}$. Younger age is a known independent factor in improved outcome for peripheral nerve regeneration ${ }^{[16]}$. Verdú et al. ${ }^{[19]}$ elegantly review the body of evidence, largely derived from animal studies, on the effects of age on the regenerative potential of nerves. This can be summarized by decrease and delay in Wallerian degeneration, decreased neurotrophic factor production and effects, increased transport time along the axon, and decreased substrate production for axonal regrowth as age increases. The result is a smaller, slower, less functional nerve in older subjects. There is a growing body of evidence on a variety of treatments including low-level laser, electrical stimulation, and growth-factor based therapies to optimize peripheral nerve regeneration. Much of the work has been done in animals, and there are a few early human trials with exciting, positive preliminary results. To date, none have been conducted on the human facial nerve.

\section{PLANNING FOR NERVE TRANSFER PROCEDURES}

Successful and consistent outcomes with nerve transfer procedures are predicated on appropriate patient selection and pre-operative planning. The etiology and duration of facial paralysis are the most important considerations when determining of a patient is a good candidate for a nerve transfer procedure or a different intervention to reanimate the face. The causes of facial nerve palsy vary tremendously and 
understanding the natural course of the causative pathology and prognosis for spontaneous recovery is critical in treatment planning. Nerve transfer procedures are most appropriate for patients with flaccid facial palsy who have viable facial musculature and a low potential for spontaneous recovery. This would include patients with discontinuity of the facial nerve or severe nerve injuries that have no recovery of function. Traditionally, 12 months are allowed for spontaneous recovery of facial function prior to surgical intervention in cases were facial nerve discontinuity is not certain. However, evidence from recent case series of patients undergoing surgery for vestibular schwannoma suggests a low probability of spontaneous recovery from complete facial paralysis if no improvement is seen within 6 months even in cases of an uninterrupted facial nerve ${ }^{[20,21]}$. Earlier re-establishment of neural continuity leads to improved reinnervation and functional outcomes. This is the case also with nerve transfer procedures ${ }^{[22]}$. Successful nerve transfer requires viable facial musculature and an intact neuromuscular junction. Achieving reinnervation as early as possible, and within the first 12 months of paralysis, is ideal. Although the success of nerve transfer procedures declines with longer duration of paralysis, successful nerve transfer have been described up to up to 24 months following denervation in adults ${ }^{[23-26]}$.

The status of the proximal facial nerve is a crucial consideration for facial reanimation procedures. Where feasible, cable grafting may be preferred to nerve transfer or combined with nerve transfer, as will be discussed later in the article. If the nerve is sacrificed in the cerebellopontine angle, the proximal stump may not be available for grafting. Similarly, the proximal nerve might not be available in other temporal bone pathologies or intracranial processes. In cases when the proximal facial nerve is not available, but the distal facial nerve branches remain viable, a nerve transfer procedure should be considered. When the facial nerve is sacrificed during oncologic head and neck surgery, the nerve is sampled for perineural spread. The presence of perineural invasion raises concerns regarding the success of nerve grafting and facial nerve regeneration. A small case series of 8 patients suggests equivalent outcomes from nerve grafting procedures performed in the presence of confirmed perineural invasion ${ }^{[27]}$. Many of these cases had positive final margins on the nerve. Definitive conclusions cannot be drawn from this limited data, but it does provide encouragement that regeneration can occur in cases of head and neck cancer and perineural spread of tumors.

When choosing a donor nerve for transfer procedure, there are several factors to consider including axonal density of the donor nerve, donor site deficits, time to reinnervation, ability to become mimetic, and availability. The status of other cranial nerves should be assessed thoroughly, with focus on the ipsilateral trigeminal and hypoglossal nerves, and the contralateral facial nerve, in particular. It is also critical to consider the status of the glossopharyngeal (cranial nerve IX) and vagus (cranial nerve X) nerves, particularly if a hypoglossal nerve transfer procedure is considered. Swallowing or articulation deficit from hypoglossal nerve transfer would be further compounded by concomitant lower cranial nerve palsy. Patient factors may also affect the success of nerve transfer procedures. Peripheral neural regeneration declines with aging and microvascular disease such as smoking or diabetes ${ }^{[19,28]}$. However, further research is necessary on their effects on facial nerve regeneration to provide evidence based clinical guidelines. The following sections in this review will discuss commonly utilized donor nerves and their advantages and disadvantages.

\section{PRIMARY REPAIR AND CABLE GRAFTING}

Prior to in depth review of nerve transfer procedures, readers must understand the benefits, and limitations, of primary nerve repair and cable grafting. Nerves undergoing repair should always be trimmed back until normal fascicles are encountered ${ }^{[29]}$. Levinthal et al. ${ }^{[30]}$ showed in their work with canines, that repair at the fascicle carried no advantage over epineural repair. When the facial nerve is injured, timely primary repair with neurorrhaphy is preferred to cable nerve graft. Green et al. ${ }^{[31]}$ examined a series of 22 patients who sustained iatrogenic facial nerve injury during otologic surgery. In their series, the best result with a cable 
graft was House-Brackmann (HB) IV compared to primary repair, for which a HB III was consistently obtained. As this study demonstrates, the best general outcome from a stand-alone cable graft procedure to the main trunk of the facial nerve is a HB III. When comparing functional outcomes between direct repair to cable grafts, symmetry at rest and with voluntary motion are worse for the cable graft group ${ }^{[32]}$. Further, more mass movement and synkinesis are more frequent for those having undergone cable grafting compared to direct neurorrhaphy ${ }^{[33]}$.

Direct nerve repair may not be feasible due to the distance between proximal and distal nerve stumps. Occasionally, significant mobilization of the nerve can be performed. However, if the direct nerve repair is under tension the vascularization of anastomosis is compromised leading to poorer results ${ }^{[34]}$. It is generally held that nerve repair or grafting procedures should be performed with operating microscope. Polarity and orientation of the nerve at inset have not been shown to have physiological or histological consequences ${ }^{[35]}$. When motor versus sensory nerve autografts were compared for facial nerve defects in animal models, no functional, electrophysiologic, or histologic differences were observed ${ }^{[36]}$. Cable grafts are often used to repair the facial nerve after ablative surgery or trauma. The facial nerve may be at risk to iatrogenic trauma during temporomandibular, head and neck, otologic, and cosmetic facial plastic procedures. Surgery to the temporomandibular joint has been reported as the etiology of $27 \%$ of iatrogenic facial nerve injuries in a recent case series ${ }^{[37]}$. And in parotidectomies, according to a large American College of Surgeon National Surgical Quality Improvement Program study, nerve sacrifice occurs in only $3.7 \%{ }^{[38]}$. Bovenzi et al. ${ }^{[38]}$ and others have importantly drawn attention to the low rate (24\%-31\%) of intraoperative nerve repair or reconstruction in those undergoing sacrifice ${ }^{[39,40]}$. Lu et al. ${ }^{[40]}$ observed that of those undergoing reanimation in the setting of radical parotid surgery, $65 \%$ had nerve-type repair sometimes in combination with slingtype procedure, while the remainder had sling-type repair only. Younger patients were more likely to undergo nerve repair procedures.

Despite the widespread recommendation to pursue cable grafting for reconstruction after facial nerve resection, the outcomes are underreported, unpredictable, and often disappointing. This is especially true when a cable graft is used to repair the main trunk of the facial nerve. However, when cable grafts are used for repair of distal branches, the repair is often quite satisfactory [Figure 1]. Limited case series are available on the effects of length of defect, age of patient, and use of adjuvant radiation. Reddy et al ${ }^{[41]}$ reported a series of patients who underwent cable graft repair of the facial nerve during radical parotid surgery; 9 of 11 reached a HB grade III 2 years after surgery and 2 of 11 patients had minimal to no improvement. Patients under the age of 30 had better outcomes. Lee et al ${ }^{[42]}$ reported their findings from a similar sized series who underwent cable grafting after parotid surgery. Using the Facial Nerve Grading Scale 2.0, they report moderate dysfunction and an average score of 14.6. In cases of head and neck malignancy, it has been observed that locoregional recurrence was no different in those undergoing nerve grafting and those who did not have reanimation at the time of primary tumor resection ${ }^{[43]}$. Further, there are several reports showing successful reanimation when patients undergo adjuvant radiotherapy to the parotid region. Case series large enough to compare outcomes with or without radiotherapy are not available $e^{[29,44-46]}$.

Options for autogenous cable nerve grafting to the facial nerve include, but are not limited to: greater auricular nerve, cervical sensory nerves, sural nerve, lateral and medial antebrachial cutaneous nerves, thoracodorsal nerve, lateral femoral cutaneous nerve, and motor nerve to vastus lateralis. The proximity of the greater auricular nerve to the facial nerve makes it a frequently utilized option during parotidectomy ${ }^{[44]}$. In the setting of radical parotid surgery with need for free tissue transfer, donor nerves are often available in the reconstructive flaps ${ }^{[47-49]}$. The sural nerve is the most used nerve for cross facial nerve transfers. The sural nerve has long length available $(30-40 \mathrm{~cm})$, consistent anatomy, ease of dissection, pure sensory function, and low morbidity ${ }^{[49,50]}$. Sensory loss over the lateral aspect of the foot is the rule with sural nerve graft ${ }^{[51]}$. Recent modifications in sural graft harvest include minimally invasive and endoscopic 


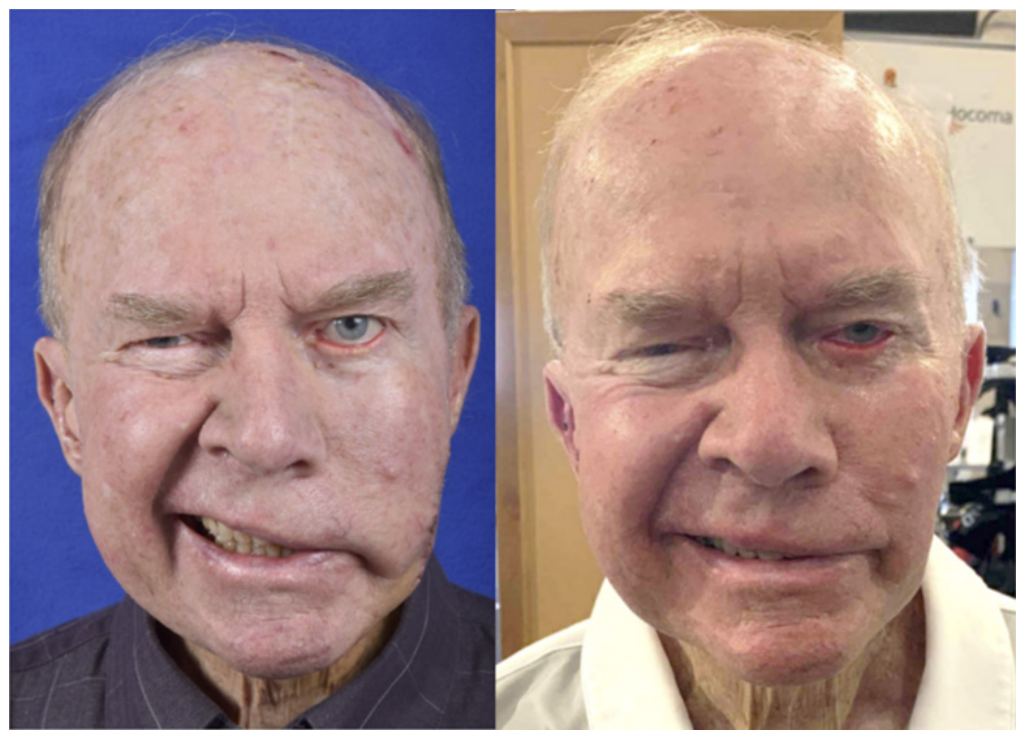

Figure 1. Seventy-eight year-old male with left-sided flaccid paralysis of the midface secondary to squamous cell carcinoma invasion of the midface branches of the facial nerve. Photo on left shows flaccid paralysis following resection. Photo to the left shows reinnervation 4 months after two cable grafts measuring $2 \mathrm{~cm}$ in length were used to repaired the affected distal branches

techniques ${ }^{[2,53]}$. The median antebrachial cutaneous nerve is preferred by some surgeons for cable graft repair ${ }^{[54]}$. Many synthetic materials have been used in place of autogenous nerve cable grafts and represent a promising area of research; however, autologous nerve grafts continue to have superior outcomes. Synthetic nerve conduits are discussed later in the review.

Readers should consider the limitations of cable grafting as a sole means for facial nerve repair. As discussed above, outcomes are unpredictable and far inferior to a direct repair, particularly when the main trunk is involved. Many contemporary techniques utilize concurrent nerve transfer with cable grafting in an effort to improve outcomes from immediate repair of sacrificed facial nerves. Following the a review of selected nerve transfer procedures, the article will discuss these exciting advances.

\section{MASSETERIC NERVE TRANSFER}

The nerve to the masseter muscle is a motor branch of the third division of the trigeminal cranial nerve. It crosses the mandibular notch and enters the substance of the masseter muscle. It travels intramuscularly, giving off several proximal branches prior to a large descending branch, which courses obliquely in the direction of the oral commissure. First reported for use with facial reanimation in 1978, the masseteric nerve is used frequently for facial reanimation procedures due to its proximity and similar diameter to the facial nerve midface branches, limited donor-site morbidity, rich motor input, and rapid recovery ${ }^{[55]}$. Masseter-to-facial nerve transfers have been described for both coaptation to the main trunk or to a midface branch for targeted zygomaticus complex reinnervation. Coaptation to a midface branch is more common in our practice as it allows powerful and targeted input to the smile musculature.

\section{Surgical technique}

While the masseteric nerve is less frequently encountered in routine head and neck oncologic surgery, consistent landmarks, and a few key tips for the approach, permit the experienced head and neck surgeon to readily become facile with its identification. The masseter nerve is reliably found in a region $3 \mathrm{~cm}$ anterior to the tragus and $1 \mathrm{~cm}$ inferior to the zygomatic arch. The so-called "subzygomatic triangle" is described as a useful guide for starting the dissection ${ }^{[56]}$. The nerve is found at a depth of $1.48+/-0.19$ $\mathrm{cm}$ deep to the submuscular aponeurotic system, with a descending branch coursing intramuscularly 


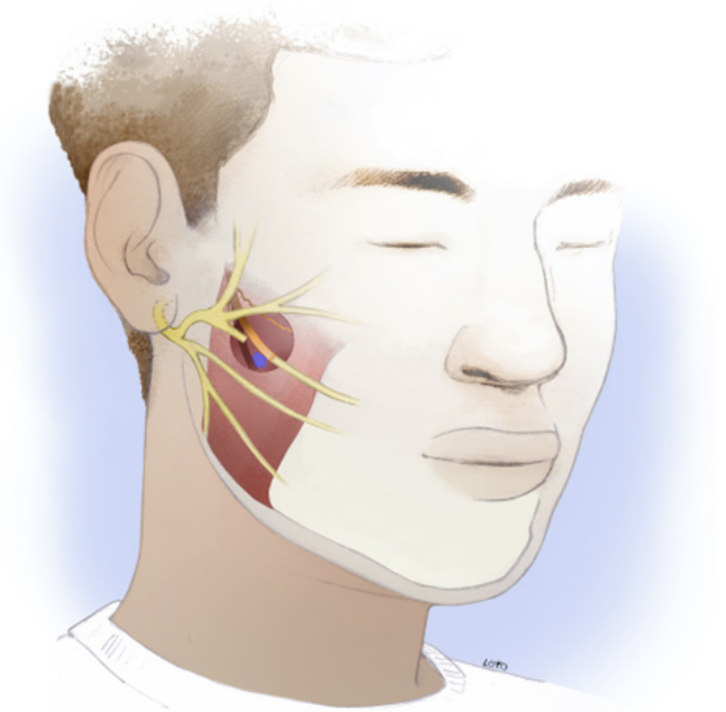

Figure 2. Diagram showing masseter nerve transfer to midfacial branch

toward the oral commissure ${ }^{[57]}$. More proximal branches can typically be spared, allowing some preserved innervation to the masseter muscle. In our practice, dissection into the muscle is aided by the use of two small Cumming's retractors. The descending branch typically courses between the middle and deep layers of the muscle, with the two layers separated by fascia. A nerve stimulator is useful to confirm identification of the nerve and avoid confusion with fascial bands. A right-angle retractor is used to place a vessel loop around the nerve, allowing gentle traction for dissection of an additional 1-2 cm distally. The nerve is then transected and transposed up to the selected facial nerve branch for coaptation [Figure 2]. In this selective operation, the main trunk of the facial nerve may be left intact to allow for spontaneous recovery, if that is still deemed a possibility. The microneural coaptation is performed under no tension with 9-0 epineural nylon sutures followed by fibrin glue sealant. The sealant is thought to prevent loss of axons by growth into adjacent soft tissue while also providing some tensile strength to the nerve and hemostatic effect in the wound. In animal studies, there are conflicting results when comparing fibrin glue to microsurgical suture technique in peripheral nerve repair ${ }^{[58,59]}$. In the absence of definitive evidence, these authors recommend microsuturing with or without use of fibrin glue in all nerve repair procedures.

\section{Outcomes}

There are several advantages the masseteric nerve possesses for use in facial reanimation. The anatomy allows the masseteric nerve to be directly coapted to a midfacial branch without use of an interposition graft. The masseteric nerve also has a rich axonal input. Coombs et al ${ }^{[60]}$ showed that the masseteric nerve contained 1,542 myelinated fibers compared to 834 in a midface branch and 100 to 200 at the distal end of a cross facial nerve graft. The masseteric to facial nerve transfer tends to show tone and movement as early as 3 months post-operative. A systematic review in 2018 on JAMA Facial Plastic Surgery found an average of 4.95 months to first movement following masseteric nerve transfer ${ }^{[61]}$. In this review, which included studies utilizing coaption to either the main trunk or a midface branch of the facial nerve, the time to recovery was quicker in the latter cohort. Two case series compare masseteric nerve transfer to hypoglossal transfer and found a faster rate of recovery with masseteric nerve transfer. Hontanilla et al. ${ }^{[62]}$ reported 2 months vs. 4.5 months and Albathi et al. ${ }^{[20]}$ reported 5.6 months vs. 10.8 months. While outcome measurements are not standardized across the literature, oral commissure excursion, facial symmetry, and clinically graded subjective scales for facial paralysis are consistently improved with masseteric nerve transfer. In one study, oral commissure excursion is measured with the Facial Asymmetry Index, which 


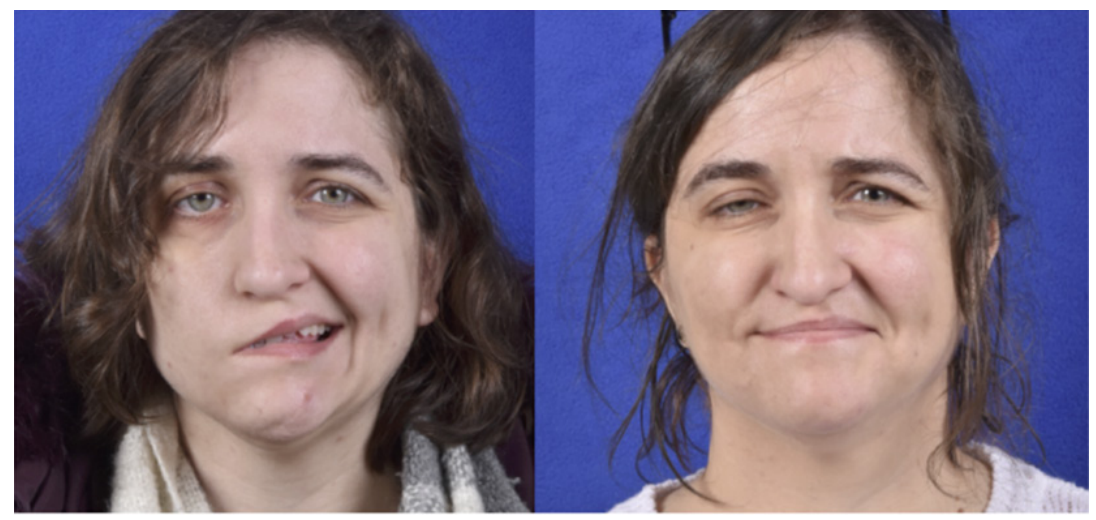

Figure 3. Thirty year-old female with 10 month history of right-sided flaccid paralysis following retrosigmoid vestibular schwannoma resection. Photo demonstrating the preoperative flaccid paralysis (left). Reanimation on smile 5 months following masseter nerve transfer to midfacial branch (right)

measures the distance between the medial canthus and oral commissure in healthy and paralyzed sides of the face ${ }^{[23]}$. Following masseteric nerve transfer, the authors report a mean difference between sides of the face at rest $(1.7 \mathrm{~mm})$ and during smile $(10.6 \mathrm{~mm})$. These values were significantly better than those in patients who underwent hypoglossal nerve transfer. In a systematic review of masseter transfer, an average of $9 \mathrm{~mm}$ of improvement in oral commissure excursion was noted, however analysis was limited due to a low number of studies reporting this outcome and incomplete data ${ }^{[20]}$. In contrast to the success seen in smile restoration for patients with flaccid paralysis, masseteric nerve transfer to the midface branches of patients with post-paralysis facial palsy and synkinesis has had limited reported success ${ }^{[63]}$.

After a masseteric nerve transfer for facial reanimation, patients perform rehabilitation to learn their new smile ("bite to smile"), allowing for a relatively effortless and natural smile [Figure 3]. While restoration of spontaneous smile was previously speculated to occur frequently, more recent evidence suggests that a true spontaneous smile is unlikely to occur ${ }^{[64,65]}$. Although patients may not need to clench their teeth, there is likely some necessary voluntary activation of the masseter required to elicit a smile. In the Spontaneous Smile Assay, patients' smiles are recorded while watching a humorous video clip. Banks et al. ${ }^{[63]}$ found that none of their 60 patients who underwent masseter nerve transfer achieved a spontaneous smile, but the authors do note that some patients were able to achieve an effortless or "open mouth" smile ${ }^{[65]}$. Reports of effortless smile with masseter nerve transfer may be due to cortical plasticity between the 5th and 7th cranial nerve nuclei or normal activation of the masseter with smiling in $40 \%$ of the population ${ }^{[6]]}$.

Masseteric nerve transfer is generally a well-tolerated operation, with some limitations and drawbacks. Anecdotally, the masseter nerve seems to provide less tone at rest than the hypoglossal nerve transfer. The lack of resting tone might be explained by the nature of the masseter muscle function, which has dense contraction with activity and little resting tone. There is minimal donor site morbidity from partial denervation of the masseter muscle as only the descending branch is divided and the robust temporalis muscle, as well as the medial pterygoid and contralateral muscles of mastication, remain unaffected during chewing. However, prandial movement of the face is often seen and was reported as "bothersome" or "very bothersome" in $12.7 \%$ of patients in one study by van Veen et al. ${ }^{[66]}$ Masseter atrophy was selfreported by $18.3 \%$ of patients in this study. Temporomandibular joint dysfunction is not considered a likely complication of masseter nerve transfer.

The masseter nerve is also commonly utilized as a source of neural input for gracilis free muscle transfer (GFMT) for smile restoration in long-standing flaccid facial paralysis. There are case reports of prior masseteric nerve transfers that fail to provide smile restoration during a nerve transfer being "recycled" successfully to innervate a GFMT. 
A

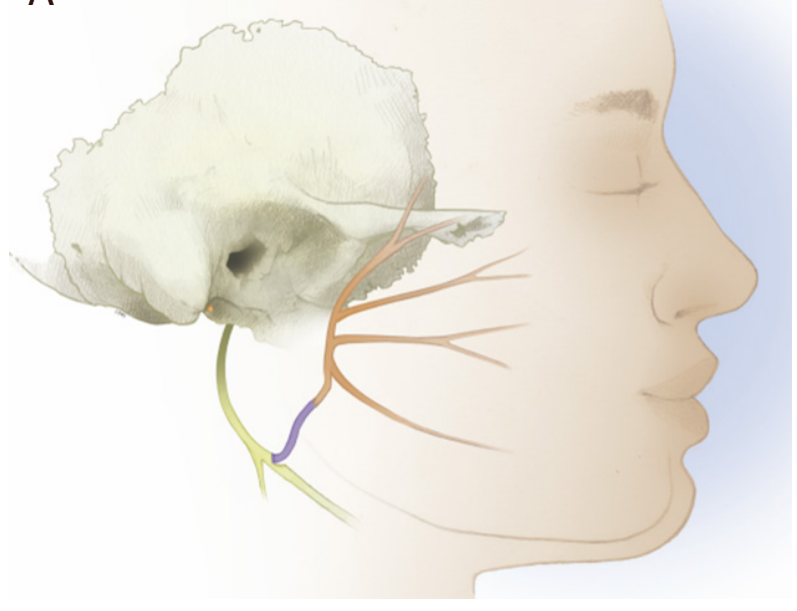

B

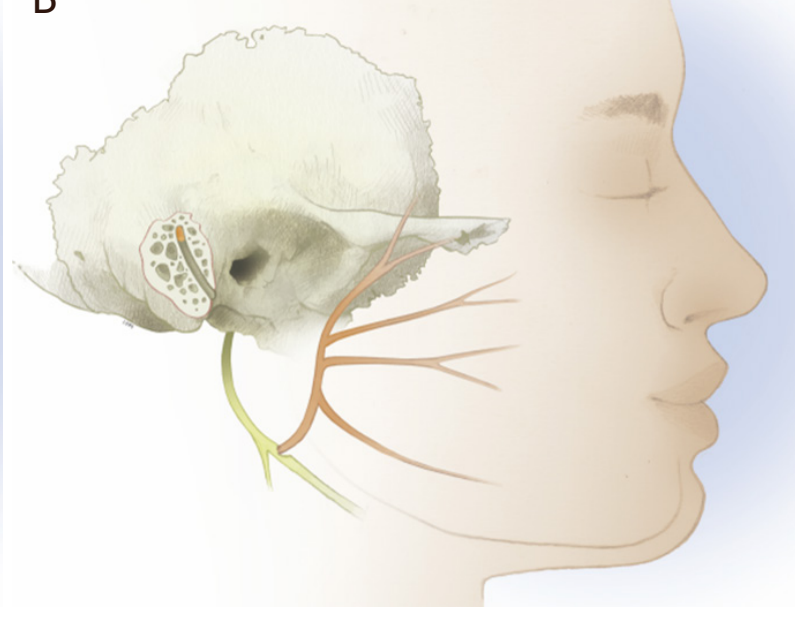

Figure 4. Diagram showing partial hypoglossal nerve transfer techniques with interposition cable graft (A) and intratemporal mobilization and transposition following mastoidectomy (B)

Another branch of the trigeminal nerve, the deep temporal nerve, is used occasionally in facial reanimation. Banks et al. ${ }^{[63]}$ utilized the deep temporal nerve on occasion to preserve the masseter nerve for possible future GFMT, if the nerve transfer is predicted to have a low probability of success for example in cases of prolonged period of denervation ${ }^{[65]}$. Recent reports of use of the deep temporal nerve for selective reinnervation of the upper face and peri-ocular musculature are an exciting development in the field ${ }^{[67,68]}$.

\section{HYPOGLOSSAL NERVE TRANSFER}

The hypoglossal nerve (CN XII) descends along the jugular foramen along the vagus (CN X) and spinal accessory (CN XI) nerves and travels in levels II, Ib and Ia of the neck to innervate the tongue. Head and neck surgeons are familiar with identifying and preserving the hypoglossal nerve, making this technique easily adoptable. The original hypoglossal nerve transfer technique from the 1970s describes sacrificing the entire hypoglossal nerve and coapting it to main trunk of the facial nerve ${ }^{[69,70]}$. This technique resulted in hemi-tongue atrophy and significant morbidity. Half of the patients reported dysarthria and one-quarter dysphagia. Problematic mass movement of the face, hypertonicity, and synkinesis routinely were frequently noted $^{[71]}$. To decrease morbidity, the technique has been modified to involve only partial hypoglossal nerve transfer. The hypoglossal nerve contains more and larger myelinated axons than the facial nerve ${ }^{[71]}$. Given that the facial nerve contains 73\% as many axons as the hypoglossal nerve, partial hypoglossal nerve transfer can achieve sufficient axonal load for successful reinnervation. Rates of dysarthria and dysphagia with partial hypoglossal nerve transfer techniques are unfortunately underreported. Extreme caution is advised when considering a hypoglossal transfer in patients with multiple lower cranial nerve palsies. Patients with brain stem cavernomas and after base of skull surgery are at particular risk for multiple cranial nerve deficits which compound to deteriorate speech and swallowing function.

\section{Surgical technique}

Partial hypoglossal nerve transfer techniques include the use of interposition grafts, splitting and mobilizing a segment of the hypoglossal nerve for transposition, and intratemporal mobilization of the main trunk of the facial nerve for transposition [Figure $4 \mathrm{~A}$ and B]. May et al. ${ }^{[72]}$ described using an interposition graft between a 30 to $40 \%$ sectioned hypoglossal nerve and the main facial nerve trunk. Arai et al. ${ }^{[73]}$ described splitting the hypoglossal nerve longitudinally from anterior to posterior to mobilize a split segment superiorly to the main trunk of the facial nerve. May et al. ${ }^{[72]}$ reported 3 of 20 patients had hemitongue atrophy and 2 recovered, while Arai et al. ${ }^{[73]}$ reported no cases of severe hemi-tongue atrophy but all 


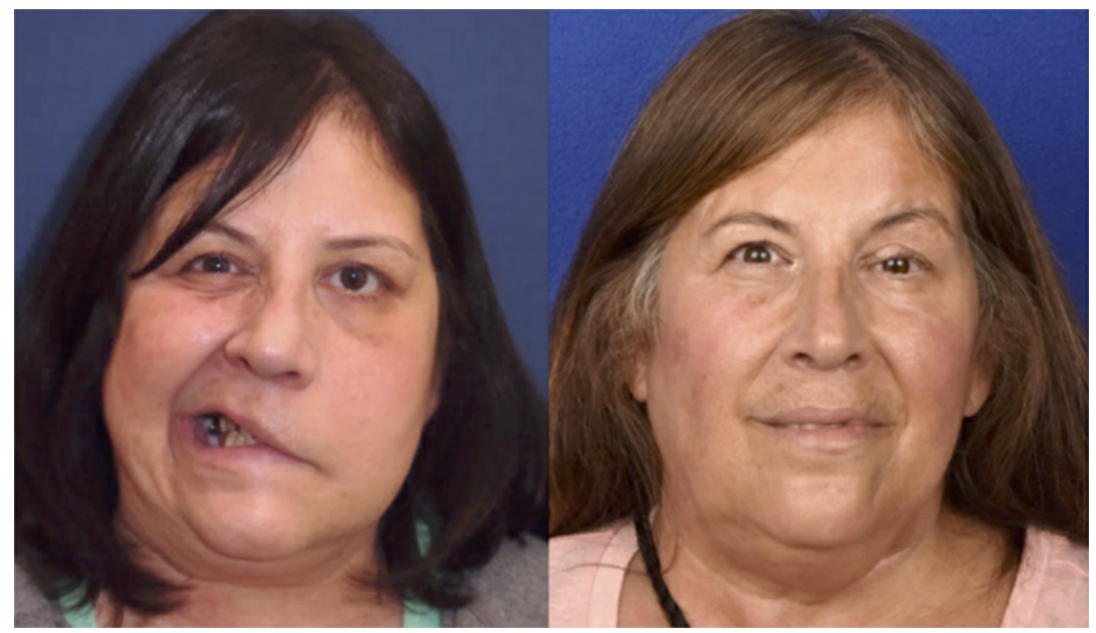

Figure 5. Fifty-seven year-old female with left sided flaccid paralysis secondary to a pontine hemorrhagic stroke. The stroke affected the masseteric (trigeminal) nerve which was not available for transfer. She underwent facial to hypoglossal nerve transfer after 10 months of flaccid paralysis. The facial nerve was transposed to the facial nerve after mastoidectomy. Photos during smile attempts during flaccid paralysis (left) and after nerve transfer (right)

(8) reported cases did have minimal to moderate tongue atrophy. Atlas and Lowinger ${ }^{[74]}$ were first to report on the use of the mobilized intratemporal facial nerve to graft to the hypoglossal nerve. Others have echoed their work with similar success ${ }^{[75-79]}$. Intratemporal mobilization of the facial nerve provides additional length to the facial nerve to allow direct coaptation to the hypoglossal nerve and minimize hypoglossal manipulation. In this procedure, a cortical mastoidectomy is performed to expose the 2nd genu and mastoid segments of the nerve. The facial nerve is then transected at the 2 nd genu and mobilized down [Figure 5]. In addition to the previously described techniques, the hypoglossal nerve may be used as a "baby-sitting" procedure in combination with a cross facial nerve graft to maintain innervation to the facial musculature while awaiting for cross facial nerve axonal growth; this is further discussed in the section of combined nerve transfers later in the review.

\section{Outcomes}

Kocchar et al. ${ }^{[79]}$ reported on the use of the intratemporal facial to hypoglossal transposition in a series of 17 patients with pre-operative HB grade of V or VI. They reported a mean time to reinnervation was 7.3 months. Fifteen of the $17(88 \%)$ had Smile Recovery scores of "very good" or "good". The authors reported significant improvements in the objective Facial Asymmetry Index score and smile excursion. Encouragingly, none of the authors using this technique reported functional issues from the tongue or even the appearance of tongue atrophy ${ }^{[68,72,80]}$. Martins et al. ${ }^{[78]}$ retrospectively compared the transposed intratemporal facial to hypoglossal technique to the classic end-to-end hypoglossal-facial transfer in 36 patients ${ }^{[80]}$. They found no significant difference in technique with respect to facial nerve function as measured by unblinded clinicians using HB scale. In this study, the authors developed a I-IV scale of tongue dysfunction based on the degree of both atrophy and deviation of the tongue; a score of IV equating to severe hemi-atrophy and deviation $>30$ degrees beyond midline and a score of I being normal ${ }^{[80]}$. Unsurprisingly, tongue function was worse with those who underwent the classic technique. $75 \%$ of patients undergoing the classic technique had severe Grade IV tongue dysfunction whereas no Grade IV tongue dysfunction was seen in the intratemporal facial to hypoglossal group and $70 \%$ in this group had no detectable tongue dysfunction.

Manni et al. ${ }^{[78]}$ reported on their outcomes for 29 patients undergoing hypoglossal-facial anastomosis, all with great auricular nerve interposition graft, by timing of reanimation surgery ${ }^{[81]}$. Interestingly they had 4 
patients with more than 2 years of paralysis undergo successful reanimation. The time to observed initial facial movement after surgery correlated with decreased time of paralysis. Movement was noted at 6.9, 8.6, and 9 months after surgery for the three groups with average pre-operative paralysis duration of 8.2, 16.5, and 30.2 months, respectively. Almost half (44\%) of their patients achieved HB III recovery. They do report HB II recovery in $20 \%$ of patients, all of whom were in the group undergoing early reanimation surgery. No hemi-tongue atrophy deficits were noted in this patient series.

The partial hypoglossal nerve transfer is an important tool for facial reanimation. Improvements in technique have significantly decreased the morbidity of the procedure. There is limited objective information available on morbidity of hypoglossal nerve transfer procedures with regards to speech and swallowing secondary to hemi-tongue atrophy. This represents an area ripe for improvement in reporting.

\section{CROSS FACE NERVE GRAFT}

When reanimating the paralyzed face, the contralateral facial nerve is the only input source that has the potential to restore volitional, spontaneous movement. First described in the 1970's, the cross facial nerve graft (CFNG) synchronizes neural transmission from the contralateral facial nerve to the paralyzed side through a long interposition graft, typically harvested from the sural nerve ${ }^{[82]}$. Variable success rates have been reported for CFNG. When a CFNG is used as a stand-alone technique, failures are often reported. In 1996, Scaramella reported their outcomes for 11 patients who underwent CFNG, noting 5 patients with good tone, 3 with fair tone, 1 with poor tone, and 2 failures ${ }^{[83]}$. Baker and Conley reported that only 6 of 10 patients in their study noted improvements ${ }^{[84]}$. Anderl described the use of multiple CFNGs tunneled subcutaneously across the forehead, midface, and lips, noting poor results in 4 of 23 patients ${ }^{[85]}$. Galli described immediate CFNG following acoustic neuroma surgery in 5 patients with acceptable results ${ }^{[86]}$. The time to reinnervation and the limited axonal load provided by a CFNG are thought to explain the variable results and high failure rates. Nerve growth occurs at 1 to $1.5 \mathrm{~mm}$ per day under optimal conditions, requiring 6 to 8 months for growth across a CFNG through a long $20 \mathrm{~cm}$ sural nerve graft ${ }^{[4]}$. As discussed previously, progressive muscle atrophy and a loss of motor end plates occurs after one year of denervation. Therefore, a stand-alone CFNG should be performed within 6 months of onset of facial paralysis to allow neural input to reach the denervated muscle while it remains receptive. Additionally, in a CFNG, neural regeneration must occur across two neurorrhaphy sites. Only 20 to 50\% of axons cross each neurorrhaphy. Low axonal load are expected across $\mathrm{CFNG}^{[87,88]}$. Furthermore, older patients have reduced potential for neural regeneration and reduced growth through nerve grafts ${ }^{[30,89,90]}$. Outcomes from CFNGs in older patients can be difficult to predict. There are no specific age recommendations for CFNGs and further research is necessary to guide clinical practice.

The unpredictable outcomes from CFNGs and long wait time for reinnervation are significant limitations. Many surgeons combine CFNG as an adjunct to other nerve transfer procedures in an effort to improve the likelihood of success of reinnervation and maintain potential for spontaneous movement. CFNG procedures may be combined with "babysitter" procedures to the decrease the length of denervation to the affected facial muscles ${ }^{[91,92]}$. In a "babysitter" procedure, a hypoglossal or masseteric nerve transfer is performed concomitantly with the first stage of the CFNG to provide neural input to the paralyzed face while awaiting axonal growth across the CFNG. In the second stage, the distal CFNG is copated to recipient branches in the paralyzed side distal to the original nerve transfer. Muscle degeneration and motor end plate loss have been prevented by the initial nerve transfer providing additional time to utilize a CFNG. The CFNG is also commonly used as a neural source for gracilis free muscle transfer (GFMT). While this review is not discussing free tissue transfer in detail, it is worth noting the GFMT surgery can be performed in staged fashion after allowing axonal growth through the CFNG, so there is limited time for denervation change in the target muscle. Even in GFMT, CFNG neurotization has higher failure rates and lower smile excursion when compared to massetric nerve ${ }^{\left[{ }^{33]}\right.}$. CFNGs have been used in other areas 
of the face, including for reinnervation to the periorbital area, with recent interest in use of platysma neurotization with a CFNG for eyelid reanimation ${ }^{[94]}$. However, there is little definitive data available on these recently described procedures.

\section{Single-stage versus two-stage cross facial nerve graft}

Although a two-staged approach for CFNGs is the more frequently utilized and accepted method, in recent years interest in the single-stage CFNG has increased. In a two stage CFNG, the goal of the first stage is to coapt the donor facial nerve to the proximal end of the nerve graft and position the distal end of the graft in the paralyzed face, without coapting to the recipient paralyzed nerve. In the second stage, typically 6-8 months later, the edges of the distal end of the graft are freshened and the graft is coapted to the recipient paralyzed facial nerve. This fresh coaptation, with a nerve graft primed with axonal regeneration, minimizes scarring across the coaptation site. In the single stage procedure, there is a prolonged period of healing at the coaptation site, during which scarring may occur and interfere with eventual axonal regeneration. Furthermore, the two-stage approach avoids sacrifice of the affected facial nerve during the first stage, allowing for possible spontaneous recovery during the waiting period, depending on the etiology of the paralysis.

Proposed advantages of the single-stage CFNG are reducing the number of surgeries, providing neurotrophic stimulation from the distal coaptation, and blocking unwanted aberrant regeneration into the distal end of the graft. Limited data is available on the success of single-stage CFNGs. Although case reports of successful single-stage CFNG in facial reanimation have been published, direct comparisons of two-stage and single-stage CFNGs are not currently available ${ }^{[88]}$. Several successful cases of singlestage CFNG with concurrent hypoglossal or masseter nerve transfers for facial reanimation have also been published ${ }^{[95-98]}$. A small retrospective study comparing single and two-stage CFNGs paired with hypoglossal transfer did not find a difference between the two cohorts ${ }^{[98]}$. In these studies, it is not possible to differentiate the contribution of each nerve used for reinnervation, making it impossible to evaluate the success of the CFNG.

Early experience from single-stage CFNG for free muscle transfer is also encouraging, when paired with another nerve transfer, commonly the masseter nerve. Animal models suggest dual innervated free muscle transfer with single stage or two-stage CFNGs have similar results ${ }^{[99,100]}$. While dual innervation free muscle transfer with single-stage CFNG and masseteric nerve for facial paralysis have been shown to the successfully restore smiles, the contribution of each nerve and direct comparison studies to two-stage CFNG dual innervation flaps are not available ${ }^{[101,102]}$.

\section{Cross facial nerve graft surgical technique}

The sural nerve is typically selected as the neural cable for CFNG given its available length of 25 to 30 $\mathrm{cm}$ and its minimal donor site morbidity. On the donor side of the face, a pre-auricular incision is used to access the normal facial nerve. For smile restoration, a midface facial nerve branch that activates the zygomaticus complex, resulting in oral commissure excursion is typically selected. This branch is typically found midway between the root of the helix and oral commissure adjacent to the anterior border of the parotid gland, 1-2 cm below the zygomatic $\operatorname{arch}^{[103]}$. The surgeon should attempt to identify a few branches in this region where the facial nerve begins to arborize anterior to the parotid gland. The largest caliber midfacial branch at the anterior border of the parotid should be selected to maximize neural input to the graft. Extensive arborization in this area of the face allows one midfacial branch to be sacrificed without significantly weakening the zygomaticus complex on this side of the face. Despite the concern of potentially weakening the contralateral smile during a CFNG, this is not appreciated, presumably a result of the extensive degree of arborization. An identical pre-auricular incision is made on the paralyzed side. If the CFNG is performed in a single stage, a suitable midface facial nerve branch for coaptation is identified 


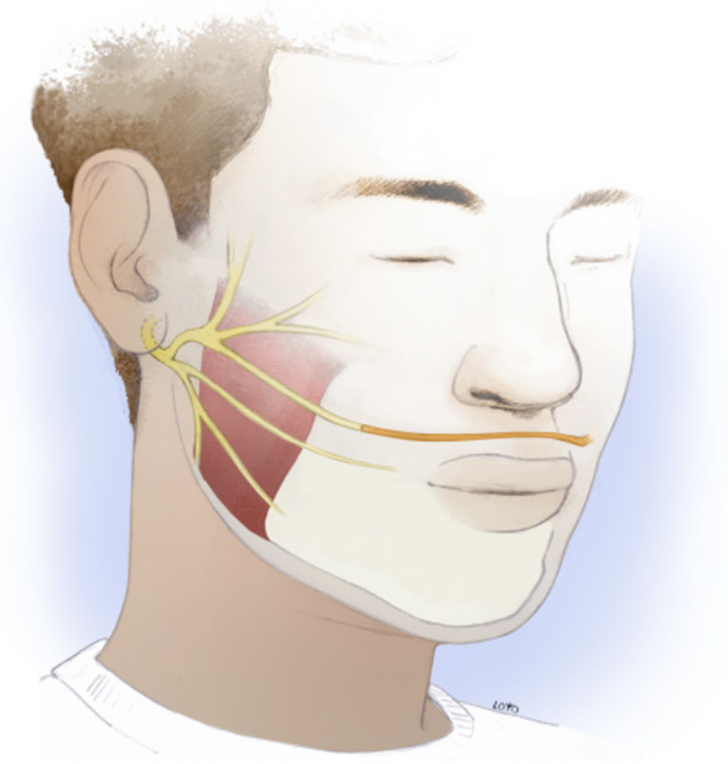

Figure 6. Diagram showing cross facial nerve graft tunneled across upper lip from midfacial branch

based on location, as the chronically paralyzed nerve will not stimulate. A subcutaneous tunnel is created from across the upper lip to connect the two wound beds [Figure 6]. A small gingivolabial incision is useful for connecting the two tunnels. The sural nerve graft is then tunneled across the incision. Most surgeons orient the nerve with the distal aspect of the nerve graft coapted to the contralateral (healthy) facial nerve branch. However, there is not definitive evidence to support orientation of the graft affects outcomes. The microneural anastomosis is performed with 9-0 nylon epineural sutures under no tension, followed by fibrin glue sealant. Fibrin glue sealant is theorized to prevent aberrant axonal growth into surrounding soft tissue; however, data on its benefit are inconclusive.

In a two-stage CFNG procedure the distal end of the CFNG is tagged with a surgical clip or a permanent suture in the wound. The Tinel sign is used to determine when it is time for the second stage as a harbinger of neural regeneration across the graft. When tapping the face in the region of the distal end of the CFNG produces a tingling sensation at the site of the donor facial nerve axons have reached the distal tip of the cable graft ${ }^{[1]}$. This finding is attributed to sensory fibers growing across the nerve graft. This process of axonal regeneration typically takes 6 to 8 months. In the second surgery, the distal tip of the cable graft is freshened and copated to a suitable recipient paralyzed facial nerve branch.

\section{OTHER COMBINATION REINNERVATION PROCEDURES}

Combination reinnervation procedures utilize input from more than one nerve to reanimate the paralyzed face. This tailored treatment approach allows us to benefit from the individual properties of different donor nerves (i.e., spontaneity, tone, axonal load) and to "uncouple" separately reinnervated areas on the face, in an attempt to prevent undesired mass movement and synkinesis.

Combining a masseter nerve transfer with cable graft repair of the facial nerve is our preferred immediate reanimation technique for addressing radical parotidectomy defects when the main trunk of the facial nerve is involved and direct repair is not possible. As described by Owusu et al. ${ }^{[104]}$, the masseter nerve is coapted to a midface facial branch to restore smile and cable grafts are used to repair remaining facial nerve branches. Here, when possible, nerve stimulation is used to confirm the midfacial branch with the greatest input to the zygomaticus complex. Confirmation with electrostimulation is often not possible 
with prolonged paralysis. In their series, Owusu et al. ${ }^{[104]}$ reported that oral commissure excursion was reestablished in all patients within 7 months and minimal synkinesis was reported. Problematic synkinesis often results when cable grafting alone is used for multiple branches, but in this series, minimal synkinesis was reported when cable grafting is combined with a masseter nerve transfer. In oncologic cases where the proximal facial nerve is not available, a combination of masseteric nerve transfer to a midface branch and partial hypoglossal nerve with a cable graft to other distal facial nerve branches has been described ${ }^{[105]}$. The masseteric nerve transfer is used to restore smile excursion, while the hypoglossal nerve transfer is used to further restore facial tone. Others have described similar techniques with use of the hypoglossal nerve and cable grafts ${ }^{[106]}$. Yamamoto described successful use of the hypoglossal nerve to "supercharge" a damaged facial nerve with end-to-side coaptation in a small case series of patients with complete and incomplete facial palsy ${ }^{[107]}$. Despite these exciting advances, there are no studies comparing these techniques to more traditional techniques and larger cases series are necessary to make definitive statement regarding their utility. Dual innervation is also described for use with free muscle transfer utilizing masseteric nerve and cross facial nerve grafts to innervate gracilis free flaps; however, discussion of these techniques is beyond the scope of this article.

\section{ARTIFICIAL CONDUITS}

Synthetic nerve conduits have consistently gained clinical popularity, yet autologous nerve grafting remains the gold standard. Synthetic nerve grafts guide axonal regrowth and range from decellularized allografts to synthetic scaffolds. The lack of well-designed randomized trials makes clinical comparison of nerve conduits to autografts impossible, particularly for the facial nerve. The off-the-shelf and ready-to-use quality of synthetic nerve conduits is appealing. The Food and Drugs Administration (FDA) has approved several products which are available for purchase. Human and porcine products are decellularized to reduce immunogenicity (AxoGen, Inc., Alachua, FL). Synthetic materials include polyglycolic acid (PGA) (Synovis Micro Companies), collagen type 1 (Integra LifeSciences Co., Plainsboro, NJ and Collagen Matrix, Inc., Franklin, TN), and caprolactone (Polyganics BV, Groningen, Netherlands) ${ }^{[108]}$. The majority of human studies evaluating nerve conduits evaluate their use in upper extremity surgery. This research suggests that synthetic neural conduits have an upper limit in maximal length for successful grafting, which may be as short at $15 \mathrm{~mm}$ and may vary depending on the nerve being grafted ${ }^{[109]}$. For the facial nerve specifically, nerve conduits have only been studied in animal models ${ }^{[110,11]}$. No human trials are available and human use is limited to individual case reports ${ }^{[112,113]}$. Furthermore, synthetic materials carry the risk of extrusion and migration, as well as foreign body reactions and fibrosis which impede neural growth ${ }^{[111]}$. Future research in peripheral nerve repair will also aim to understand the role of Schwann cells and the microenvironment in nerve regeneration. Efforts to improve peripheral nerve regeneration by utilizing neurotrophic growth factors, cell-based therapies, and vascularized nerve grafts are currently underway. Rigorous human studies of these interventions remain necessary to better understand outcomes and clinical applicability ${ }^{[14-117]}$.

\section{SPECIAL CONSIDERATION IN PEDIATRIC FACIAL PARALYSIS}

Although rarely indicated, nerve transfer techniques currently used in adults may be applied to children with acquired facial paralysis. It is important to consider that depending on the cause of paralysis, children may experience spontaneous recovery. In cases where recovery is unlikely, surgical facial nerve reanimation should be considered. Cross face nerve transfers are exciting options for children given their enhanced regeneration potential. Preserved facial muscles and an intact neuromuscular junction are necessary for a nerve transfers to be successful. Congenital cases in which these are absent are not amenable to reanimation with these techniques and require free muscle transfer. The most common causes of acquired facial paralysis in children are infection and trauma. In the past, acute otitis media was the leading cause of facial paralysis, but advances in antibiotics and vaccines have reduced its incidence to less than $0.005 \%{ }^{[118]}$. 
Currently in the United States, Lyme disease is the main cause of pediatric facial paralysis, particularly in the New England and the Mid-Atlantic regions. Lyme disease presents with facial paralysis in children at a much higher rate than in adults and may occur in $50 \%$ of affected children ${ }^{[119]}$. Bell's palsy is the most common cause of facial paralysis in adults and, at a lower rate, can affect children as well ${ }^{[120]}$. Ninety-five percent of children with Bell's palsy recover fully ${ }^{[121]}$. Trauma during birth, falls, motor vehicle collisions, iatrogenic injury during surgery for intracranial tumors, temporal bone pathology, and vascular or lymphatic malformations can also cause facial paralysis in children ${ }^{[122]}$. Less common causes of pediatric facial paralysis include malignancy and systemic disease. Bell's palsy and birth trauma are generally expected to recover spontaneously and should first be observed ${ }^{[123]}$.

In general, children experience better and faster functional outcomes after peripheral nerve repair than adults ${ }^{[124]}$. Aging affects the central nervous system's neuroplasticity as well as peripheral nerve regeneration ${ }^{[21]}$. In children, enhanced neural regeneration makes cross-facial nerve transfers an enticing option. It is likely that cross-facial nerve grafts are more successful in children than adults, but further research is necessary in this area. Although young children are more likely to successfully reinnervate after prolonged facial paralysis than adults, the specific duration of paralysis and age cutoffs are still not known. As in adults, better outcomes are expected in children after early repair, and intervention is recommended as early as possible. Likewise, prolonged facial paralysis in children may not be amenable to nerve transfers.

\section{CONCLUSION}

Nerve transfer procedures have the potential to restore innervation to the native facial musculature. The success of nerve transfers depends on proper patient selection and early reinnervation. Utilizing nerve transfer as early as possible, and ideally during the first 12 months of paralysis, is recommended. Prolonged paralysis is frequently not amenable to nerve transfer. This review highlights key advantages and limitations of the various donor nerves. The masseteric nerve provides excellent smile restoration after coapation to midfacial nerve branches with minimal morbidity. Several modifications to the hypoglossal nerve transfer have been described to limit its morbidity to speech and swallowing. The cross facial nerve, while appealing and able to achieve a true spontaneous smile, has limitations in terms of axonal load, time to reinnervation, unpredictable outcomes, and utility in older patients who have less regenerative potential. Finally, there are exciting new developments in the field; combining reanimation techniques to harness advantages of various donor nerves, and research in peripheral nerve regeneration.

\section{DECLARATIONS}

\section{Acknowledgments}

The authors would like to acknowledge Juan Carlos Loyo for his assistance with the medical illustrations. Illustrations were used with advanced permission from Mr. Loyo.

\section{Authors' contributions}

Manuscript concept and planning: Loyo M, Dougherty W

Conducted literature review and interpretation: Loyo M, Dougherty W, Liebman R

Preparation of medical illustrations: Loyo M

Composition and preparation of manuscript: Loyo M, Dougherty W, Liebman R

Manuscript edits and revisions: Loyo M, Dougherty W, Liebman R

\section{Availability of data and materials}

Not applicable.

\section{Financial support and sponsorship}

None. 


\section{Conflicts of interest}

All authors declared that there are no conflicts of interest.

\section{Ethical approval and consent to participate}

Not applicable.

\section{Consent for publication}

Written, informed consent was obtained in advance from patients or their legal guardian for publication of patient photos. Supporting documents are available upon request.

\section{Copyright}

(c) The Author(s) 2021.

\section{REFERENCES}

1. Ishii LE, Nellis JC, Boahene KD, Byrne P, Ishii M. The importance and psychology of facial expression. Otolaryngol Clin North Am 2018;51:1011-7.

2. Seddon HJ. Peripheral Nerve Injuries. Glasgow Med J 1943;139:61-75.

3. Sunderland S. A classification of peripheral nerve injuries producing loss of function. Brain 1951;74:491-516.

4. Funakoshi H, Frisén J, Barbany G, et al. Differential expression of mRNAs for neurotrophins and their receptors after axotomy of the sciatic nerve. J Cell Biol 1993;123:455-65

5. Menorca RM, Fussell TS, Elfar JC. Nerve physiology: mechanisms of injury and recovery. Hand Clin 2013;29:317-30.

6. Mackinnon SE, Dellon AL, Hudson AR, Hunter DA. Chronic human nerve compression--a histological assessment. Neuropathol Appl Neurobiol 1986;12:547-65.

7. Shyng S, Salpeter M. Effect of reinnervation on the degradation rate of junctional acetylcholine receptors synthesized in denervated skeletal muscles. J Neurosci 1990;10:3905-15.

8. Miledi R, Slater CR. On the degeneration of rat neuromuscular junctions after nerve section. $J$ Physiol 1970;207:507-28.

9. Dieu T, Johnstone BR, Newgreen DF. Genes and nerves. J Reconstr Microsurg 2005;21:179-86.

10. Blesch A, Tuszynski MH. GDNF gene delivery to injured adult CNS motor neurons promotes axonal growth, expression of the trophic neuropeptide CGRP, and cellular protection. J Comp Neurol 2001;436:399-410.

11. Tetzlaff W, Alexander S, Miller F, Bisby M. Response of facial and rubrospinal neurons to axotomy: changes in mRNA expression for cytoskeletal proteins and GAP-43. J Neurosci 1991;11:2528-44.

12. Hur EM, Saijilafu, Zhou FQ. Growing the growth cone: remodeling the cytoskeleton to promote axon regeneration. Trends Neurosci 2012;35:164-74.

13. Geraldo S, Gordon-Weeks PR. Cytoskeletal dynamics in growth-cone steering. J Cell Sci 2009;122:3595-604 .

14. Burnett MG, Zager EL. Pathophysiology of peripheral nerve injury: a brief review. Neurosurg Focus 2004;16:E1.

15. Lohmeyer JA, Sommer B, Siemers F, Mailänder P. Nerve injuries of the upper extremity-expected outcome and clinical examination. Plast Surg Nurs 2009;29:88-93; quiz 94-5.

16. Miehlke A, Stennert E, Schuster R, Schätzle W, Haubrich J. [Regeneration of peripheral nerve after effect of ionizing radiation]. ORL $J$ Otorhinolaryngol Relat Spec 1972;34:88-100.

17. Stearns M. Some factors affecting nerve regeneration in relation to radiotherapy. $J R$ Soc Med. 1983;76:743-6.

18. Nguyen QT, Sanes JR, Lichtman JW. Pre-existing pathways promote precise projection patterns. Nat Neurosci 2002;5:861-7.

19. Verdú E, Ceballos D, Vilches JJ, Navarro X. Influence of aging on peripheral nerve function and regeneration. J Peripher Nerv Syst 2000;5:191-208.

20. Albathi M, Oyer S, Ishii LE, Byrne P, Ishii M, Boahene KO. Early nerve grafting for facial paralysis after cerebellopontine angle tumor resection with preserved facial nerve continuity. JAMA Facial Plast Surg 2016;18:54-60.

21. Rivas A, Boahene KD, Bravo HC, Tan M, Tamargo RJ, Francis HW. A model for early prediction of facial nerve recovery after vestibular schwannoma surgery. Otol Neurotol 2011;32:826-33.

22. Zhang S, Hembd A, Ching CW, Tolley P, Rozen SM. Early masseter to facial nerve transfer may improve smile excursion in facial paralysis. Plast Reconstr Surg Glob Open 2018;6:e2023.

23. Wu P, Chawla A, Spinner RJ, et al. Key changes in denervated muscles and their impact on regeneration and reinnervation. Neural Regen Res 2014:9:1796-809.

24. Conley J. Hypoglossal crossover--122 cases. Trans Sect Otolaryngol Am Acad Ophthalmol Otolaryngol 1977;84:ORL-763-8.

25. Gavron JP, Clemis JD. Hypoglossal-facial nerve anastomosis: a review of forty cases caused by facial nerve injuries in the posterior fossa. Laryngoscope 1984;94:1447-50.

26. Kunihiro T, Kanzaki J, Yoshihara S, Satoh Y, Satoh A. Hypoglossal-facial nerve anastomosis after acoustic neuroma resection: influence of the time anastomosis on recovery of facial movement. ORL J Otorhinolaryngol Relat Spec 1996;58:32-5.

27. Wax MK, Kaylie DM. Does a positive neural margin affect outcome in facial nerve grafting? Head Neck 2007;29:546-9. 
28. Büttner R, Schulz A, Reuter M, et al. Inflammaging impairs peripheral nerve maintenance and regeneration. Aging Cell 2018;17:e12833.

29. Ray WZ, Mackinnon SE. Management of nerve gaps: autografts, allografts, nerve transfers, and end-to-side neurorrhaphy. Exp Neurol 2010;223:77-85.

30. Levinthal R, Brown WJ, Rand RW. Comparison of fascicular, interfascicular and epineural suture techniques in the repair of simple nerve lacerations. J Neurosurg 1977;47:744-50.

31. Green JD Jr, Shelton C, Brackmann DE. Surgical management of iatrogenic facial nerve injuries. Otolaryngol Head Neck Surg 1994;111:606-10.

32. Spector JG, Lee P, Peterein J, Roufa D. Facial nerve regeneration through autologous nerve grafts: a clinical and experimental study. Laryngoscope 1991;101:537-54.

33. Jandali D, Revenaugh PC. Facial reanimation: an update on nerve transfers in facial paralysis. Curr Opin Otolaryngol Head Neck Surg 2019;27:231-6.

34. Terzis J, Faibisoff B, Williams B. The nerve gap: suture under tension vs. graft. Plast Reconstr Surg 1975;56:166-170.

35. Nakatsuka H, Takamatsu K, Koshimune M, Imai Y, Enomoto M, Yamano Y. Experimental study of polarity in reversing cable nerve grafts. J Reconstr Microsurg 2002;18:509-15.

36. Ali SA, Rosko AJ, Hanks JE, et al. Effect of motor versus sensory nerve autografts on regeneration and functional outcomes of rat facial nerve reconstruction. Sci Rep 2019;9:8353.

37. Hohman MH, Bhama PK, Hadlock TA. Epidemiology of iatrogenic facial nerve injury: a decade of experience. Laryngoscope 2014; $124: 260-5$

38. Bovenzi CD, Ciolek P, Crippen M, Curry JM, Krein H, Heffelfinger R. Reconstructive trends and complications following parotidectomy: incidence and predictors in 11,057 cases. J Otolaryngol Head Neck Surg 2019;48:64.

39. Crawford KL, Stramiello JA, Orosco RK, Greene JJ. Advances in facial nerve management in the head and neck cancer patient. Curr Opin Otolaryngol Head Neck Surg 2020;28:235-40.

40. Lu GN, Villwock MR, Humphrey CD, Kriet JD, Bur AM. Analysis of facial reanimation procedures performed concurrently with total parotidectomy and facial nerve sacrifice. JAMA Facial Plast Surg 2019;21:50-5.

41. Reddy PG, Arden RL, Mathog RH. Facial nerve rehabilitation after radical parotidectomy. Laryngoscope 1999;109:894-9.

42. Lee MC, Kim DH, Jeon YR, et al. Functional outcomes of multiple sural nerve grafts for facial nerve defects after tumor-ablative surgery. Arch Plast Surg 2015;42:461-8.

43. Park W, Park J, Park SI, et al. Clinical outcomes and management of facial nerve in patients with parotid gland cancer and pretreatment facial weakness. Oral Oncol 2019;89:144-9.

44. Hontanilla B, Qiu SS, Marré D. Effect of postoperative brachytherapy and external beam radiotherapy on functional outcomes of immediate facial nerve repair after radical parotidectomy. Head Neck 2014;36:113-9.

45. Gullane PJ, Havas TJ. Facial nerve grafts: effects of postoperative irradiation. J Otolaryngol 1987;16:112-115.

46. Ciolek PJ, Prendes BL, Fritz MA. Comprehensive approach to reestablishing form and function after radical parotidectomy. Am $J$ Otolaryngol 2018;39:542-7.

47. Biglioli F, Colombo V, Pedrazzoli M, et al. Thoracodorsal nerve graft for reconstruction of facial nerve branching. J Craniomaxillofac Surg 2014;42:e8-14.

48. Urken ML, Weinberg H, Vickery C, Biller HF. The neurofasciocutaneous radial forearm flap in head and neck reconstruction: a preliminary report. Laryngoscope 1990;100:161-73.

49. Piedra Buena IT, Fichman M. Sural nerve graft. In: StatPearls. Treasure Island (FL): StatPearls Publishing; May 21, 2020.

50. Mahakkanukrauh P, Chomsung R. Anatomical variations of the sural nerve. Clin Anat 2002;15:263-6.

51. Lapid O, Ho ES, Goia C, Clarke HM. Evaluation of the sensory deficit after sural nerve harvesting in pediatric patients. Plast Reconstr Surg 2007;119:670-4.

52. Spinks TJ, Adelson PD. Pediatric sural nerve harvest: a fully endoscopic technique. Neurosurgery 2009;64:360-3; discussion 363-4.

53. Cinal H, Barin EZ, Kara M, et al. A new method to harvest the sural nerve graft. Eurasian J Med 2020;52:12-5.

54. Haller JR, Shelton C. Medial antebrachial cutaneous nerve: a new donor graft for repair of facial nerve defects at the skull base. Laryngoscope 1997;107:1048-52.

55. Spira M. Anastomosis of masseteric nerve to lower division of facial nerve for correction of lower facial paralysis. Preliminary report. Plast Reconstr Surg 1978;61:330-4.

56. Collar RM, Byrne PJ, Boahene KD. The subzygomatic triangle: rapid, minimally invasive identification of the masseteric nerve for facial reanimation. Plast Reconstr Surg 2013;132:183-8.

57. Borschel GH, Kawamura DH, Kasukurthi R, Hunter DA, Zuker RM, Woo AS. The motor nerve to the masseter muscle: an anatomic and histomorphometric study to facilitate its use in facial reanimation. J Plast Reconstr Aesthet Surg 2012;65:363-6.

58. Sameem M, Wood TJ, Bain JR. A systematic review on the use of fibrin glue for peripheral nerve repair. Plast Reconstr Surg 2011;127:2381-90.

59. Sánchez-Ocando M, Gavilán J, Penarrocha J, et al. Facial nerve repair: the impact of technical variations on the final outcome. Eur Arch Otorhinolaryngol 2019;276:3301-8.

60. Coombs CJ, Ek EW, Wu T, Cleland H, Leung MK. Masseteric-facial nerve coaptation--an alternative technique for facial nerve reinnervation. J Plast Reconstr Aesthet Surg 2009;62:1580-8.

61. Murphey AW, Clinkscales WB, Oyer SL. Masseteric nerve transfer for facial nerve paralysis: a systematic review and meta-analysis. JAMA Facial Plast Surg 2018;20:104-10. 
62. Hontanilla B, Marré D. Comparison of hemihypoglossal nerve versus masseteric nerve transpositions in the rehabilitation of short-term facial paralysis using the facial clima evaluating system. Plast Reconstr Surg 2012;130:662e-72e.

63. Banks CA, Jowett N, Iacolucci C, Heiser A, Hadlock TA. Five-year experience with fifth-to-seventh nerve transfer for smile. Plast Reconstr Surg 2019;143:1060e-71e.

64. Schaverien M, Moran G, Stewart K, Addison P. Activation of the masseter muscle during normal smile production and the implications for dynamic reanimation surgery for facial paralysis. J Plast Reconstr Aesthet Surg 2011;64:1585-8.

65. Klebuc MJ. Facial reanimation using the masseter-to-facial nerve transfer. Plast Reconstr Surg 2011;127:1909-15.

66. van Veen MM, Dusseldorp JR, Quatela O, et al. Patient experience in nerve-to-masseter-driven smile reanimation. $J$ Plast Reconstr Aesthet Surg 2019;72:1265-71.

67. Mahan MA, Sivakumar W, Weingarten D, Brown JM. Deep temporal nerve transfer for facial reanimation: anatomic dissections and surgical case report. Oper Neurosurg (Hagerstown) 2018;15:81-8.

68. Karagoz H, Ozturk S, Malkoc I, Diyarbakir S, Demirkan F. Anatomy of the anterior deep temporal nerve: implications for neurotization in blinking restoration in facial paralysis. Ann Plast Surg 2015;75:316-8.

69. Conley J, Baker DC. Hypoglossal-facial nerve anastomosis for reinnervation of the paralyzed face. Plast Reconstr Surg 1979;63:63-72.

70. Klebuc M, Shenaq SM. Donor nerve selection in facial reanimation surgery. Semin Plast Surg 2004;18:53-60.

71. Asaoka K, Sawamura Y, Nagashima M, Fukushima T. Surgical anatomy for direct hypoglossal-facial nerve side-to-end "anastomosis". $J$ Neurosurg 1999;91:268-75.

72. May M, Sobol SM, Mester SJ. Hypoglossal-facial nerve interpositional-jump graft for facial reanimation without tongue atrophy. Otolaryngol Head Neck Surg 1991;104:818-25.

73. Arai H, Sato K, Yanai A. Hemihypoglossal-facial nerve anastomosis in treating unilateral facial palsy after acoustic neurinoma resection. J Neurosurg 1995;82:51-4.

74. Atlas MD, Lowinger DS. A new technique for hypoglossal-facial nerve repair. Laryngoscope 1997;107:984-91.

75. Sawamura Y, Abe H. Hypoglossal-facial nerve side-to-end anastomosis for preservation of hypoglossal function: results of delayed treatment with a new technique. J Neurosurg 1997;86:203-6.

76. Campero A, Ajler P, Socolovsky M, Martins C, Rhoton A. Facial nerve reanimation by partial section of the hypoglossal nerve and mini mastoidectomy. Surg Neurol Int 2012;3:S400-4.

77. Slattery WH 3rd, Cassis AM, Wilkinson EP, Santos F, Berliner K. Side-to-end hypoglossal to facial anastomosis with transposition of the intratemporal facial nerve. Otol Neurotol 2014;35:509-13.

78. Martins RS, Socolovsky M, Siqueira MG, Campero A. Hemihypoglossal-facial neurorrhaphy after mastoid dissection of the facial nerve: results in 24 patients and comparison with the classic technique. Neurosurgery 2008;63:310-6; discussion 317.

79. Kochhar A, Albathi M, Sharon JD, Ishii LE, Byrne P, Boahene KD. Transposition of the intratemporal facial to hypoglossal nerve for reanimation of the paralyzed face: the VII to XII transposition technique. JAMA Facial Plast Surg 2016;18:370-8.

80. Rebol J, Milojković V, Didanovic V. Side-to-end hypoglossal-facial anastomosis via transposition of the intratemporal facial nerve. Acta Neurochir (Wien) 2006;148:653-7; discussion 657.

81. Manni JJ, Beurskens CH, van de Velde C, Stokroos RJ. Reanimation of the paralyzed face by indirect hypoglossal-facial nerve anastomosis. The American Journal of Surgery 2001;182:268-73.

82. Scaramella LF. Anastomosis between the two facial nerves. Laryngoscope 1975;85:1359-66.

83. Scaramella LF. Cross-face facial nerve anastomosis: historical notes. Ear Nose Throat J 1996;75:343-54.

84. Baker DC, Conley J. Facial nerve grafting: a thirty year retrospective review. Clin Plast Surg 1979;6:343-60.

85. Anderl H. Reconstruction of the face through cross-face-nerve transplantation in facial paralysis. Chir Plastica 1973;2:17-45.

86. Galli SK, Valauri F, Komisar A. Facial reanimation by cross-facial nerve grafting: report of five cases. Ear Nose Throat J 2002;81:25-9.

87. Snyder-Warwick AK, Fattah AY, Zive L, Halliday W, Borschel GH, Zuker RM. The degree of facial movement following microvascular muscle transfer in pediatric facial reanimation depends on donor motor nerve axonal density. Plast Reconstr Surg 2015;135:370e-81e.

88. Terzis JK, Wang W, Zhao Y. Effect of axonal load on the functional and aesthetic outcomes of the cross-facial nerve graft procedure for facial reanimation. Plast Reconstr Surg 2009;124:1499-512.

89. Braam MJ, Nicolai JP. Axonal regeneration rate through cross-face nerve grafts. Microsurgery 1993;14:589-91.

90. Hembd A, Nagarkar P, Perez J, et al. Correlation between facial nerve axonal load and age and its relevance to facial reanimation. Plast Reconstr Surg 2017;139:1459-64.

91. Terzis JK, Tzafetta K. The "babysitter" procedure: minihypoglossal to facial nerve transfer and cross-facial nerve grafting. Plast Reconstr Surg 2009;123:865-76.

92. Henstrom DK. Masseteric nerve use in facial reanimation. Curr Opin Otolaryngol Head Neck Surg 2014;22:284-90.

93. Bhama PK, Weinberg JS, Lindsay RW, Hohman MH, Cheney ML, Hadlock TA. Objective outcomes analysis following microvascular gracilis transfer for facial reanimation: a review of 10 years' experience. JAMA Facial Plast Surg 2014;16:85-92.

94. Biglioli F, Zago M, Allevi F, et al. Reanimation of the paralyzed lids by cross-face nerve graft and platysma transfer. J Craniomaxillofac Surg 2018;46:521-6.

95. In igo F, Ysunza A, Rojo P, Trigos I. Recovery of facial palsy after crossed facial nerve grafts. British Journal of Plastic Surgery 1994;47:312-7.

96. Yamamoto Y, Sasaki S, Sekido M, et al. Alternative approach using the combined technique of nerve crossover and cross-nerve grafting for reanimation of facial palsy. Microsurgery 2003;23:251-6.

97. Park SO, Ha JH, Kim IK, Jin US, Chang H. Single-stage cross-facial nerve grafting has a result equivalent to that of two-stage cross- 
facial nerve grafting. Microsurgery 2020;40:175-82.

98. Bianchi B, Ferri A, Ferrari S, et al. Cross-facial nerve graft and masseteric nerve cooptation for one-stage facial reanimation: principles, indications, and surgical procedure. Head Neck 2014;36:235-40.

99. Urso-Baiarda F, Grobbelaar AO. A comparison of one- versus two-stage surgery in an experimental model of functional muscle transfer with interposed nerve grafting. J Plast Reconstr Aesthet Surg 2009;62:1042-7.

100. Rab M, Haslik W, Grünbeck M, et al. Free functional muscle transplantation for facial reanimation: experimental comparison between the one- and two-stage approach. J Plast Reconstr Aesthet Surg 2006;59:797-806.

101. Biglioli F, Bayoudh W, Colombo V, Pedrazzoli M, Rabbiosi D. Double innervation (facial/masseter) on the gracilis flap, in the middle face reanimation in the management of facial paralysis: a new concept. Ann Chir Plast Esthet 2013;58:89-95.

102. Watanabe Y, Akizuki T, Ozawa T, Yoshimura K, Agawa K, Ota T. Dual innervation method using one-stage reconstruction with free latissimus dorsi muscle transfer for re-animation of established facial paralysis: simultaneous reinnervation of the ipsilateral masseter motor nerve and the contralateral facial nerve to improve the quality of smile and emotional facial expressions. $J$ Plast Reconstr Aesthet Surg 2009;62:1589-97.

103. Dorafshar AH, Borsuk DE, Bojovic B, et al. Surface anatomy of the middle division of the facial nerve: Zuker's point. Plast Reconstr Surg 2013;131:253-7.

104. Owusu JA, Truong L, Kim JC. Facial Nerve Reconstruction With Concurrent Masseteric Nerve Transfer and Cable Grafting. JAMA Facial Plast Surg 2016;18:335-9.

105. Joseph AW, Kim JC. Management of Flaccid Facial Paralysis of Less Than Two Years' Duration. Otolaryngol Clin North Am 2018;51:1093-105.

106. Volk GF, Pantel M, Streppel M, Guntinas-Lichius O. Reconstruction of complex peripheral facial nerve defects by a combined approach using facial nerve interpositional graft and hypoglossal-facial jump nerve suture. Laryngoscope 2011;121:2402-5.

107. Yamamoto Y, Sekido M, Furukawa H, Oyama A, Tsutsumida A, Sasaki S. Surgical rehabilitation of reversible facial palsy: facial-hypoglossal network system based on neural signal augmentation/neural supercharge concept. J Plast Reconstr Aesthet Surg 2007;60:223-31.

108. Gaudin R, Knipfer C, Henningsen A, Smeets R, Heiland M, Hadlock T. Approaches to peripheral nerve repair: generations of biomaterial conduits yielding to replacing autologous nerve grafts in craniomaxillofacial Surgery. Biomed Res Int 2016;2016:3856262.

109. Safa B, Buncke G. Autograft Substitutes: Conduits and Processed Nerve Allografts. Hand Clin 2016;32:127-40.

110. Matsumine H, Sasaki R, Yamato M, Okano T, Sakurai H. A polylactic acid non-woven nerve conduit for facial nerve regeneration in rats. J Tissue Eng Regen Med 2014;8:454-62.

111. Shi Y, Zhou L, Tian J, Wang Y. Transplanting neural stem cells in nerve conduit to promote rats facial nerve regeneration. Lin Chung Er Bi Yan Hou Tou Jing Wai Ke Za Zhi 2012;26:1040-2.

112. Gunn S, Cosetti M, Roland JT Jr. Processed allograft: novel use in facial nerve repair after resection of a rare racial nerve paraganglioma. Laryngoscope 2010;120 Suppl 4:S206.

113. Navissano M, Malan F, Carnino R, Battiston B. Neurotube for facial nerve repair. Microsurgery 2005;25:268-71.

114. Cui Q. Actions of Neurotrophic factors and their signaling pathways in neuronal survival and axonal regeneration. $M N$ 2006;33:155-80.

115. Hadlock T, Sundback C, Koka R, Hunter D, Cheney M, Vacanti J. A novel, biodegradable polymer conduit delivers neurotrophins and promotes nerve regeneration. Laryngoscope 1999;109:1412-6.

116. Oliveira JT, Almeida FM, Biancalana A, et al. Mesenchymal stem cells in a polycaprolactone conduit enhance median-nerve regeneration, prevent decrease of creatine phosphokinase levels in muscle, and improve functional recovery in mice. Neuroscience 2010;170:1295-303.

117. Saffari TM, Bedar M, Hundepool CA, Bishop AT, Shin AY. The role of vascularization in nerve regeneration of nerve graft. Neural Regen Res 2020;15:1573-9.

118. Gaio E, Marioni G, de Filippis C, Tregnaghi A, Caltran S, Staffieri A. Facial nerve paralysis secondary to acute otitis media in infants and children. J Paediatr Child Health 2004;40:483-6.

119. Tveitnes D, Øymar K, Natås O. Acute facial nerve palsy in children: how often is it lyme borreliosis? Scand J Infect Dis 2007;39:425-31.

120. Holland NJ, Bernstein JM. Bell’s palsy. BMJ Clin Evid. 2014;2014:1204.

121. Peitersen E. Bell's palsy: the spontaneous course of 2,500 peripheral facial nerve palsies of different etiologies. Acta Otolaryngol Suppl 2002;4-30

122. Fattah A, Borschel GH, Zuker RM. Reconstruction of facial nerve injuries in children. J Craniofac Surg 2011;22:782-8.

123. Duval M, Daniel SJ. Facial nerve palsy in neonates secondary to forceps use. Arch Otolaryngol Head Neck Surg 2009;135:634-6.

124. Barrios C, de Pablos J. Surgical management of nerve injuries of the upper extremity in children: a 15-year survey. J Pediatr Orthop 1991;11:641-5. 